ECCOMAS

\section{Proceedia}

COMPDYN 2021

$8^{\text {th }}$ ECCOMAS Thematic Conference on Computational Methods in Structural Dynamics and Earthquake Engineering M. Papadrakakis, M. Fragiadakis (eds.) Streamed from Athens, Greece, 28 - 30 June 2021

\title{
VULNERABILITY ASSESSMENT OF MONUMENTAL ARTWORKS USING CONTACT TIME-HISTORY ANALYSIS
}

\author{
Raffaele Gagliardo $^{1}$, Michele Godio ${ }^{2}$, Lucrezia Cascini ${ }^{1}$, Francesco Portioli $^{1}$ and \\ Raffaele Landolfo ${ }^{1}$ \\ ${ }^{1}$ Department of Structures for Engineering and Architecture, University of Naples "Federico II", Italy \\ via Forno Vecchio 36, 80134 Naples, Italy \\ raffaele.gagliardo@unina.it, fportiol@unina.it, lucrezia.cascini@unina.it, landolfo@unina.it \\ ${ }^{2}$ RISE Research Institutes of Sweden \\ Brinellgatan 4, 50462 Borås, Sweden \\ michele.godio@ri.se
}

\begin{abstract}
Strategies for the protection of the Cultural Heritage priceless value are highly demanded, being both earthquake and support movement (and a combination of the two of them) severe threats for their safety and integrity. To this scope, computer-based numerical formulations have been representing a powerful tool for the simulation of expected loss in terms of pieces of art damages, with the scope to save them as much as possible. In this framework, the conference paper is devoted to the vulnerability assessment of monumental artworks using dynamic analysis in a rigid block modelling environment.

The numerical formulation adopts a discrete rigid block-based model, where the mortar joints contribution is accounted for by frictional, no-tension interfaces between the masonry units. The procedure adopted to solve the formulation is based on a dual variational problem where equilibrium, kinematic and failure conditions equations are involved at the same time, and which is solved via mathematical programming.

An application to a system of two blocks vertically stacked, one representing the support and one representing the artefact, subjected to free rocking motion will be proposed in the paper. The main scope is to investigate the seismic response of such a system, which is typical for most of museum's collections (e.g., statues). The computational efficiency and accuracy of the proposed numerical strategy will be discussed.
\end{abstract}

Keywords: Masonry block structures; Non-linear time history analysis, Free rocking motion, Mathematical programming. 


\section{INTRODUCTION}

The possibility to develop computational strategy for the investigation of museum collections behaviour against seismic-induced dynamic actions represents a challenging task, playing a crucial role in the artworks integrity protection. The response of blocky structures, such as monumental statues made of stone blocks, against lateral forces is typically characterized by rocking behaviour [1-3].

The development and use of analytical and numerical tools for the investigation of blocky structures and historical masonry monuments subjected to different loading conditions by using both static and dynamic approaches is a widespread topic in literature [4-33]. Various numerical approaches are available in literature for the investigation of the dynamic response of multi-block structures and types undergoing rocking. Among those, the interest in the use of Non-Smooth Contact Dynamics (NSCD) methods has been growing in the recent years, essentially due to the advantageous possibility to account for the blocks interactions through a system made of both equilibrium and complementary conditions. In this framework, NSCD approach represent a valid alternative to common modeling approaches such as finite element method (FEM) and discrete element method (DEM) [34-37].

The use of NSCD technique has been increasing especially in the analysis of the structural response of masonry structures [38]-[40], where fast and accurate algorithms are available in the literature for the numerical solution of the formulations proposed for the mathematical programming problem arising from the conditions governing the contact dynamics [41-44].

In this paper we adopt a simple formulation for dynamic analysis of blocky structures aiming to investigate the rocking behaviour of a system of two blocks, comparable to the configuration of a monumental statue typical of museum's collections standing on its base. The aim of this research is to assess the computational efficiency of the in-house numerical procedure and to investigate to which extent it can be properly adopted in the prediction of the rocking behaviour of museum's artefacts to save them against any possible loss or damage. It is worth noting that the modelling approach for contact interfaces can be regarded as the extension to the dynamic field of a contact point formulation developed for limit analysis of collections of polyhedral rigid blocks.

The paper is organized as follows: the dynamic formulation is described in section 2 in terms of static and kinematic variables as well as the problem formulated to govern the behaviour of the rigid block model. Section 3 deals with the numerical application of the adopted procedure to the case study of a two blocks system subjected to free rocking motion already considered in literature.

\section{THE RIGID BLOCK DYNAMIC MODEL}

The proposed numerical model is composed by a collection of quadrangular rigid blocks $i$ interacting by means of contact points $k$ located at the vertexes of contact surfaces $j$ (Figure 1a). The behaviour of contact interfaces is governed by a no-tension and associative frictional model under the assumption of infinite compressive strength. The dynamic model is formulated according to the approach proposed in $[45,46]$ for granular materials.

The contact variables are represented by the internal forces located at contact point $k$, which are essentially the shear and normal force (Figure 1b), collected in the vector $\boldsymbol{c}_{\boldsymbol{k}}$.

The relative displacement rates, both tangential $\Delta u_{t k}$ and normal $\Delta u_{n k}$, represent the kinematic variables associated to the contact forces in a virtual work sense. They are finally collected in the vector $\boldsymbol{\Delta u}$ (Figure 1c).

The centroid of the rigid block $i$ is attached by the external loads and the position of the block centroid is collected in the vector $\boldsymbol{x}_{\boldsymbol{i}}$ as described in equation (1) and Figure $1 \mathrm{~b}$. 


$$
\boldsymbol{x}_{\boldsymbol{i}}=\left[\begin{array}{lll}
x_{i} & z_{i} & \omega_{i}
\end{array}\right]^{T}
$$

$\theta$-method is used to discretize the equations of motions, as described in equations (2) and (3) with regard to time $t=t_{0}+\Delta t$.

$$
\begin{gathered}
\alpha(t)=\frac{v-v_{0}}{\Delta t} \\
v(t)=\frac{1}{\theta}\left[\frac{\Delta x}{\Delta t}-(1-\theta) v_{0}\right]
\end{gathered}
$$

being $\Delta x=x-x_{0}$ the displacement vector, $x_{0}$ the known position and $v_{0}$ the known velocity at $t_{0}$ and $0.5<\theta \leq 0.5$.

The incremental equation (2) allows to formulate the equation of motion of the collection of rigid blocks using a contact point model as described in the next equation (4):

$$
\bar{M} \Delta x+A_{0} c=\bar{f}_{0}
$$

where $\boldsymbol{A}_{\boldsymbol{0}}$ is the contact equilibrium matrix, $\overline{\boldsymbol{M}}=\frac{1}{\theta \Delta t^{2}} \boldsymbol{M}$ is related to the mass matrix $\boldsymbol{M}$ which collects the mass and the inertia moment of each block and $\overline{\boldsymbol{f}}_{0}=\boldsymbol{f}+\overline{\boldsymbol{M}} v_{0} \Delta t$.

Ad-hoc expression are formulated to account for non-penetration condition at potential contact point, by using the so-called Signorini unilateral contact condition.

Finally, sliding failure condition at contact interfaces is governed by a Coulomb friction law, expressed by the following equation (5).

$$
\pm t_{k}-\mu n_{k} \leq 0
$$

being $\mu$ the value of friction coefficient.

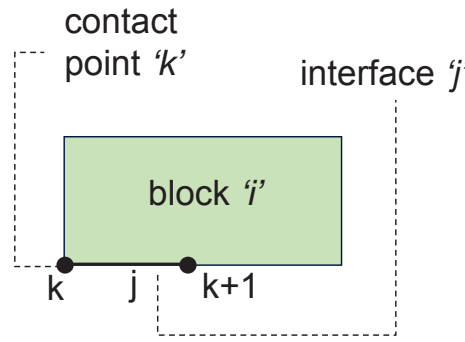

a)

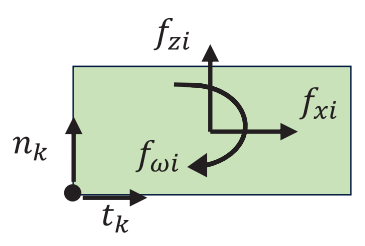

b)

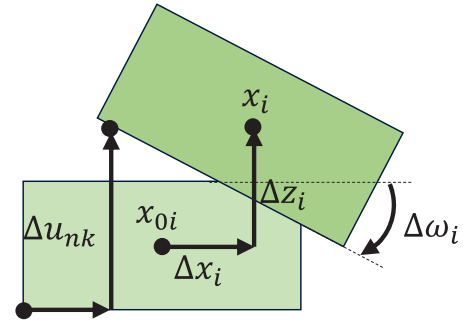

c)

Figure 1. Rigid block dynamic model: (a) Rigid block $i$, interface $j$ and contact point $k$; (b) contact forces and (c) kinematic variables at block centroid $i$, and contact point $k$.

\subsection{Formulation of the mathematical programming problem}

The dynamic problem can be expressed by an equations system which collect the equilibrium equations, the kinematic and the failure conditions in a typical linear complementarity problem (LCP). In this framework, the contact dynamics problem can be posed as described in equation (6), where $\boldsymbol{Y}^{\boldsymbol{T}}$ is the matrix of failure condition, $\lambda$ is the vector of flow multipliers and $\boldsymbol{g}_{0}$ is the vector collecting initial gaps at each contact point.

The problem expressed in equation (6) is uncoupled in two dual quadratic programming problems, a force-based and a displacement-based problem, respectively. In this way, the 
computational costs significantly decrease thanks to the possibility to use efficient solution algorithms.

$$
\begin{gathered}
{\left[\begin{array}{ccc}
\bar{M} & \cdot & \boldsymbol{A}_{0} \\
\cdot & \cdot & -\boldsymbol{Y}^{T} \\
-\boldsymbol{A}_{0}^{T} & \boldsymbol{Y} & \cdot
\end{array}\right]_{n x n}\left[\begin{array}{c}
\Delta x \\
\lambda \\
c
\end{array}\right]_{n x 1}+\left[\begin{array}{l}
\boldsymbol{y} \\
\cdot
\end{array}\right]=\left[\begin{array}{c}
\overline{\boldsymbol{f}}_{0} \\
\cdot \\
-\boldsymbol{g}_{0}
\end{array}\right]} \\
\text { s.t. } \quad-\boldsymbol{y} \geq 0 \quad \lambda \geq 0 \quad \boldsymbol{y}^{T} \lambda=0
\end{gathered}
$$

It is worth noting that the dynamic problem formulated in the equation (6) is formally equivalent to a classic limit equilibrium problem when the dynamic forces and contact gaps tend to zero. An incremental procedure was implemented to solve the optimization problem assuming kinematic variables derived by Lagrange multipliers and updating the block position and gaps values per each step.

The analyses were carried out a $3.50 \mathrm{GHz}$ Intel Xeon Processor E5-1650 with $16.0 \mathrm{~GB}$ of RAM. The value of algorithm parameter $\theta$ for time discretization was set equal to 0.7 and time increment was set in the range 0.001-0.002 s.

\section{NUMERICAL APPLICATION TO A TWO-BLOCK SYSTEM SUBJECTED TO FREE ROCKING MOTION}

The dynamic numerical procedure described in the previous section is here applied to the case study of a two-block system undergoing to free rocking. This case study was previously investigated in [47]. The geometrical properties of the two blocks are showed in Figure 2a, being equivalent to the example performed in [47]. The first block has a slenderness ratio $H_{1} / B_{1}$ equal to 1 whereas the second one has a slenderness ratio $H_{2} / B_{2}$ equal to 2.5 . The base widths are $B_{1}=1.25 \mathrm{~m}$ and $B_{2}=1.0 \mathrm{~m}$ respectively. As for the material properties, the two blocks are considered homogeneous, with a weight for unit volume $\rho_{1}=\rho_{2}=2500 \mathrm{~kg} / \mathrm{m}^{3}$. The investigated case study is characterized by a value of the starting rotation angles $\theta_{1}=\theta_{2}=$ $0.15 \mathrm{rad}$ and zero starting angular velocities for both the considered blocks.
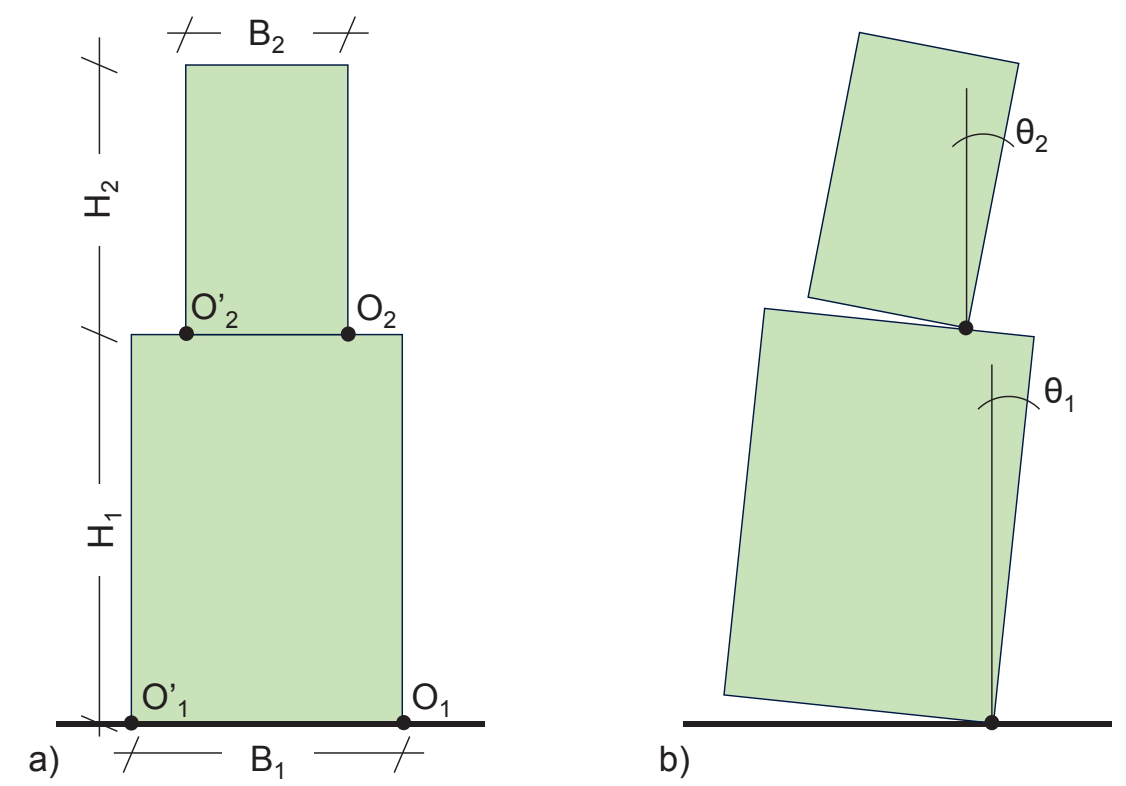

Figure 2. Two-block system: (a) geometrical properties and (b) example of configuration during free rocking motion. 
The outcomes of the simulation are reported in Figure 3. According to [47], starting from the initial configuration, the angles of rotation of the two blocks, $\theta_{1}$ and $\theta_{2}$, tend to decrease due to the oscillation movement, and this occurs with a faster rate for the block at the base. In the first part of the motion, the two blocks move as one-single block rocking about the point $O_{1}$, until the occurrence of an impact at the foundation. After the impact, the two blocks start to independently rock and other impacts occur up to the rest. As for the outcomes obtained with the proposed rigid block dynamic model, the curve showed in Figure 3 deals with the rotation angle $\theta_{2}$ of the upper block around the point $O_{2}$. The results are in a very good agreement with those obtained in [47] until the first impact of the upper block. After this initial stage, the second rotation is somewhat different with respect to the rotation predicted in [47]. Nevertheless, the two curves are very close, and so are the maximum oscillations obtained by the two models. The comparison is, therefore, very satisfying. With regard to the final stage, i.e. after the second impact of the upper block, the results obtained with the proposed rigid block dynamic model tends to predict a faster rocking performance compared with the results obtained in [47]: a higher number of impacts (i.e. change of rotation) is exhibited by the upper blocks. Finally, the two models come to a rest step at about 3.5 seconds analysis.

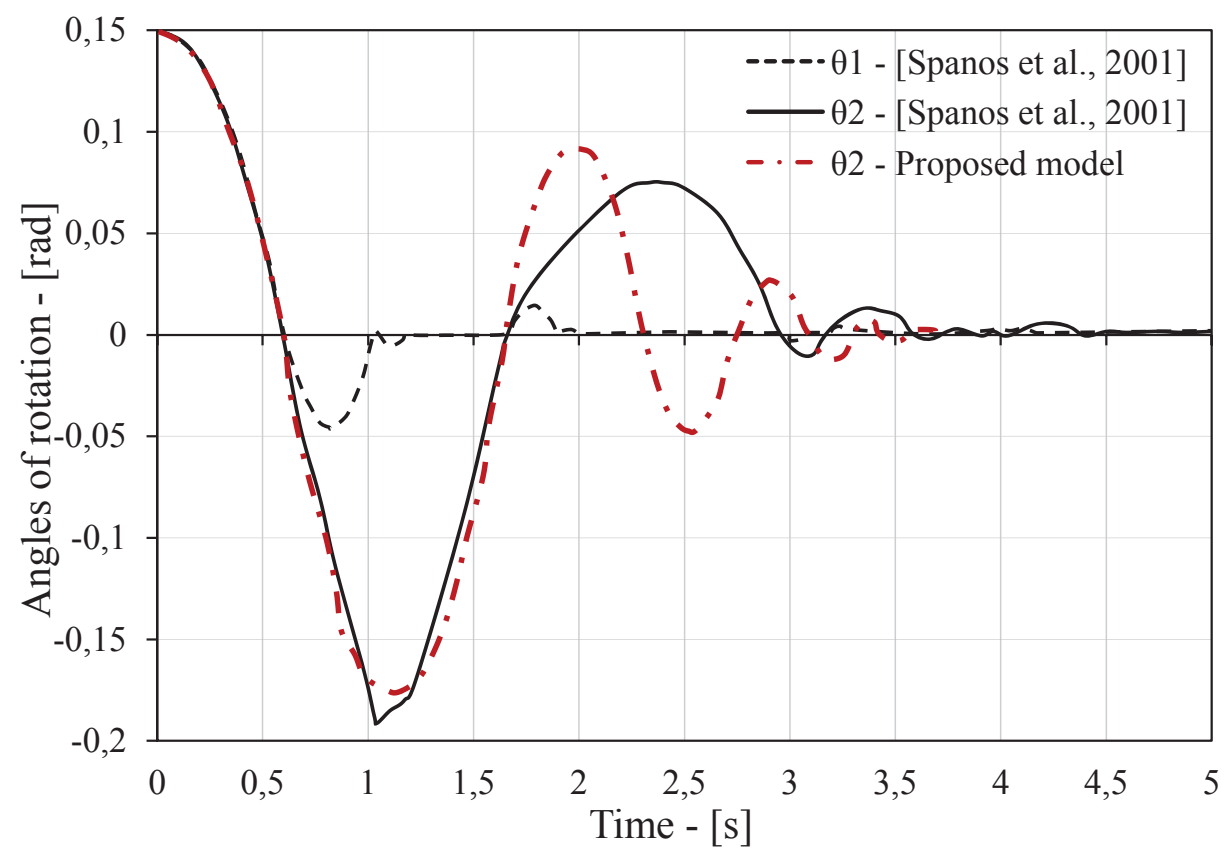

Figure 3. Free vibration response of a two-block system. Comparison with the results obtained in [47].

\section{CONCLUSIONS}

In this paper an in-house rigid block model for contact time-history analysis was described. The computational strategy is particularly suitable to investigate the response of stackedblocks objects subjected to ground excitation. From this point of view, the dynamic model could represent a useful numerical tool for the vulnerability assessment of museum's collections affected by seismic-induced action, aiming to the protection of such artworks against earthquakes events. The capabilities of the proposed formulation were tested on a case study of a two-block system experiencing free rocking motion, already investigated in literature. The outcomes showed high potentialities of the adopted strategy in the prediction of the rocking behaviour of blocky objects. 


\section{REFERENCES}

[1] O. A. Shawa, G. de Felice, A. Mauro, and L. Sorrentino, "Out-of-plane seismic behaviour of rocking masonry walls," Earthq. Eng. Struct. Dyn., vol. 41, no. 5, pp. 949-968, 2012.

[2] S. Lagomarsino, "Seismic assessment of rocking masonry structures," Bull. Earthq. Eng., vol. 13, no. 1, pp. 97-128, 2015.

[3] M. J. DeJong and E. G. Dimitrakopoulos, "Dynamically equivalent rocking structures," Earthq. Eng. Struct. Dyn., vol. 43, no. 10, pp. 1543-1563, 2014.

[4] C. Casapulla, L. Giresini, and P. B. Lourenço, "Rocking and kinematic approaches for rigid block analysis of masonry walls: State of the art and recent developments," Buildings, vol. 7, no. 3, 2017.

[5] G. De-Felice and M. Malena, "Failure pattern prediction in masonry," J. Mech. Mater. Struct., vol. 14, no. 5, pp. 663-682, 2019.

[6] M. F. Funari, A. Mehrotra, and P. B. Lourenço, "A tool for the rapid seismic assessment of historic masonry structures based on limit analysis optimisation and rocking dynamics," Appl. Sci., vol. 11, no. 3, pp. 1-22, 2021.

[7] M. F. Funari, S. Spadea, P. Lonetti, F. Fabbrocino, and R. Luciano, "Visual programming for structural assessment of out-of-plane mechanisms in historic masonry structures," J. Build. Eng., vol. 31, 2020.

[8] S. Galassi, N. Ruggieri, and G. Tempesta, "A Novel Numerical Tool for Seismic Vulnerability Analysis of Ruins in Archaeological Sites," Int. J. Archit. Herit., vol. 14, no. 1, pp. 1-22, 2020.

[9] S. Galassi, M. L. Satta, N. Ruggieri, and G. Tempesta, "In-plane and out-of-plane seismic vulnerability assessment of an ancient colonnade in the archaeological site of Pompeii (Italy)," in Procedia Structural Integrity, 2020, vol. 29, pp. 126-133.

[10] S. Galassi and G. Tempesta, "The Matlab code of the method based on the Full Range Factor for assessing the safety of masonry arches," MethodsX, vol. 6, pp. 1521-1542, 2019.

[11] S. Galassi and G. Tempesta, "Porta San Giorgio in Florence. Rigid block model analysis for thecrack pattern interpretation," in COMPDYN Proceedings, 2019, vol. 1, pp. 651-662.

[12] A. I. Giouvanidis and E. G. Dimitrakopoulos, "Rocking amplification and strongmotion duration," Earthq. Eng. Struct. Dyn., vol. 47, no. 10, pp. 2094-2116, 2018.

[13] A. I. Giouvanidis and Y. Dong, "Seismic loss and resilience assessment of singlecolumn rocking bridges," Bull. Earthq. Eng., vol. 18, no. 9, pp. 4481-4513, 2020.

[14] L. Giresini, M. Fragiacomo, and P. B. Lourenço, "Comparison between rocking analysis and kinematic analysis for the dynamic out-of-plane behavior of masonry walls," Earthq. Eng. Struct. Dyn., vol. 44, no. 13, pp. 2359-2376, 2015.

[15] L. Giresini, F. Solarino, O. Paganelli, D. V. Oliveira, and M. Froli, "ONE-SIDED rocking analysis of corner mechanisms in masonry structures: Influence of geometry, energy dissipation, boundary conditions," Soil Dyn. Earthq. Eng., vol. 123, pp. 357$370,2019$.

[16] L. Giresini, F. Solarino, F. Taddei, and G. Mueller, "Experimental estimation of energy dissipation in rocking masonry walls restrained by an innovative seismic dissipator (LICORD)," Bull. Earthq. Eng., vol. 19, no. 5, pp. 2265-2289, 2021.

[17] N. Grillanda, A. Chiozzi, G. Milani, and A. Tralli, "Tilting plane tests for the ultimate shear capacity evaluation of perforated dry joint masonry panels. Part II: Numerical analyses," Eng. Struct., vol. 228, 2021. 
[18] N. Grillanda, G. Milani, S. Ghosh, B. Halani, and M. Varma, "SHM of a severely cracked masonry arch bridge in India: Experimental campaign and adaptive NURBS limit analysis numerical investigation," Constr. Build. Mater., vol. 280, 2021.

[19] W. G. Lasciarrea, A. Amorosi, D. Boldini, G. de Felice, and M. Malena, "Jointed Masonry Model: A constitutive law for 3D soil-structure interaction analysis," Eng. Struct., vol. 201, 2019.

[20] D. Malomo and M. J. DeJong, "A Macro-Distinct Element Model (M-DEM) for simulating the in-plane cyclic behavior of URM structures," Eng. Struct., vol. 227, 2021.

[21] D. Malomo, A. Mehrotra, and M. J. DeJong, "Distinct element modeling of the dynamic response of a rocking podium tested on a shake table," Earthq. Eng. Struct. Dyn., vol. 50, no. 5, pp. 1469-1475, 2021.

[22] D. Malomo, R. Pinho, and A. Penna, "Applied Element Modelling of the Dynamic Response of a Full-Scale Clay Brick Masonry Building Specimen with Flexible Diaphragms," Int. J. Archit. Herit., vol. 14, no. 10, pp. 1484-1501, 2020.

[23] A. Mehrotra and M. J. DeJong, "A methodology to account for interface flexibility and crushing effects in multi-block masonry collapse mechanisms," Meccanica, vol. 55, no. 6, pp. 1237-1261, 2020.

[24] A. Mehrotra and M. J. DeJong, "A CAD-interfaced dynamics-based tool for analysis of masonry collapse mechanisms," Eng. Struct., vol. 172, pp. 833-849, 2018.

[25] N. A. Nodargi and P. Bisegna, "A unifying computational approach for the lowerbound limit analysis of systems of masonry arches and buttresses," Eng. Struct., vol. $221,2020$.

[26] N. A. Nodargi and P. Bisegna, "A new computational framework for the minimum thrust analysis of axisymmetric masonry domes," Eng. Struct., vol. 234, 2021.

[27] A. Orduña and A. G. Ayala, "Non-linear dynamic analysis of ancient masonry structures by 3D rigid block models," in AIP Conference Proceedings, 2015, vol. 1702.

[28] G. Pancani, S. Galassi, L. Rovero, L. Dipasquale, E. Fazzi, and G. Tempesta, "Seismic vulnerability assessment of the triumphal arch of caracalla in volubilis (Morocco): Past events and provisions for the future," in International Archives of the Photogrammetry, Remote Sensing and Spatial Information Sciences - ISPRS Archives, 2020, vol. 54, no. M-1, pp. 435-442.

[29] F. Solarino, L. Giresini, and D. V. Oliveira, "Mitigation of amplified response of restrained rocking walls through horizontal dampers," in Proceedings of the International Conference on Structural Dynamic , EURODYN, 2020, vol. 2, pp. 42924303.

[30] G. Tempesta and S. Galassi, "Safety evaluation of masonry arches. A numerical procedure based on the thrust line closest to the geometrical axis," Int. J. Mech. Sci., vol. 155, pp. 206-221, 2019.

[31] P. Zampieri, M. Amoroso, and C. Pellegrino, "The masonry buttressed arch on spreading support," Structures, vol. 20, pp. 226-236, 2019.

[32] P. Zampieri, N. Simoncello, and C. Pellegrino, "Structural behaviour of masonry arch with no-horizontal springing settlement," Frat. ed Integrita Strutt., vol. 12, no. 43, pp. 182-190, 2018.

[33] P. Zampieri, N. Simoncello, and C. Pellegrino, "Seismic capacity of masonry arches with irregular abutments and arch thickness," Constr. Build. Mater., vol. 201, pp. 786806, 2019.

[34] V. Acary and B. Brogliato, Numerical methods for nonsmooth dynamical systems. Berlin: Springer, 2008. 
[35] M. Jean, "The non-smooth contact dynamics method," Comput. Methods Appl. Mech. Eng., vol. 177, no. 3-4, pp. 235-257, 1999.

[36] J. V. Lemos, "Discrete element modeling of masonry structures," Int. J. Archit. Herit., vol. 1, no. 2, pp. 190-213, 2007.

[37] P. Lotstedt, "MECHANICAL SYSTEMS OF RIGID BODIES SUBJECT TO UNILATERAL CONSTRAINTS.," SIAM J. Appl. Math., vol. 42, no. 2, pp. 281-296, 1982.

[38] B. Chetouane, F. Dubois, M. Vinches, and C. Bohatier, "NSCD discrete element method for modelling masonry structures," Int. J. Numer. Methods Eng., vol. 64, no. 1, pp. 65-94, 2005.

[39] A. Rafiee, M. Vinches, and C. Bohatier, "Modelling and analysis of the Nîmes arena and the Arles aqueduct subjected to a seismic loading, using the Non-Smooth Contact Dynamics method," Eng. Struct., vol. 30, no. 12, pp. 3457-3467, 2008.

[40] G. Lancioni, S. Lenci, Q. Piattoni, and E. Quagliarini, "Dynamics and failure mechanisms of ancient masonry churches subjected to seismic actions by using the NSCD method: The case of the medieval church of S. Maria in Portuno," Eng. Struct., vol. 56, pp. 1527-1546, 2013.

[41] E. D. Andersen, C. Roos, and T. Terlaky, "On implementing a primal-dual interiorpoint method for conic quadratic optimization," Math. Program. Ser. B, vol. 95, no. 2, pp. 249-277, 2003.

[42] A. Tasora and M. Anitescu, "A matrix-free cone complementarity approach for solving large-scale, nonsmooth, rigid body dynamics," Comput. Methods Appl. Mech. Eng., vol. 200, no. 5-8, pp. 439-453, 2011.

[43] D. E. Stewart and J. C. Trinkle, "An implicit time-stepping scheme for rigid body dynamics with inelastic collisions and coulomb friction," Int. J. Numer. Methods Eng., vol. 39, no. 15, pp. 2673-2691, 1996.

[44] M. Anitescu and F. A. Potra, "A time-stepping method for stiff multibody dynamics with contact and friction," Int. J. Numer. Methods Eng., vol. 55, no. 7, pp. 753-784, 2002.

[45] K.-W. Lim, K. Krabbenhoft, and J. E. Andrade, "A contact dynamics approach to the Granular Element Method,” Comput. Methods Appl. Mech. Eng., vol. 268, pp. 557-573, 2014.

[46] K. Krabbenhoft, J. Huang, M. V. Da Silva, and A. V. Lyamin, "Granular contact dynamics with particle elasticity," Granul. Matter, vol. 14, no. 5, pp. 607-619, 2012.

[47] P. D. Spanos, P. C. Roussis, and N. P. A. Politis, "Dynamic analysis of stacked rigid blocks," Soil Dyn. Earthq. Eng., vol. 21, no. 7, pp. 559-578, 2001. 